Papers in Evolutionary Economic Geography

$$
\text { \# } 17.27
$$

Regional diversification and green employment in US Metropolitan Areas

Nicolò Barbieri, Davide Consoli

Utrecht University

Urban \& Regional research centre Utrecht 


\title{
Regional diversification and green employment in US Metropolitan Areas
}

\author{
Nicolò Barbieri ${ }^{ \pm}$and Davide Consoli ${ }^{\dagger}$ \\ ${ }^{ \pm}$Department of Economics and Management, University of Ferrara, Ferrara (Italy) and \\ SEEDS (Sustainability, Environmental Economics and Dynamics Studies) \\ ${ }^{\dagger}$ INGENIO (CSIC-UPV), Valencia (Spain)
}

\begin{abstract}
This paper analyses whether and to what extent regional diversification enables or thwarts green employment in US Metropolitan Areas (MAs) between 2006 and 2014. The recent debate on related and unrelated variety provides the conceptual frame for our study. The main findings are two. First, unrelated diversification is a positive and significant predictor of green employment growth. Second, this effect differs across occupational categories: while unrelated variety at industry level favours the growth of mid- to low-skill green jobs, unrelated variety at occupational level favours high- to mid-skill green jobs. Overall, local related diversification has very little impact.
\end{abstract}

Keywords: Green employment; Variety; Diversification. 


\section{Introduction}

At the core of the intense debate about climate change stands the expectation that dealing with new or revised criteria of environmental sustainability will bring about opportunities but, also, challenges associated with the necessity to adapt the structure and the organization of economies. How does such an adjustment process play out at the regional level? What are the tangible signs that local economies are, for lack of a better word, greening? And, what are the structural factors that enable or impede following this path? The present paper deals with these questions by focusing on the determinants of green regional diversification in Metropolitan Areas (MAs) of the United States (US). Committing to this line of inquiry requires a number of premises.

First, we focus on the dynamics of local labour market and, in particular, on the changes in employment of green occupations. Following recent studies that focus on the effects of technological change on the skill content of occupations (Autor, Levy and Murnane, 2003; Acemoglu and Autor, 2011), we use local occupational structures as a proxy for the growth of local green economies. This choice is grounded in the belief that modern economies are built on knowledge, and that work and employment are the vehicles through which individual know-how is applied to productive activities (Consoli and Rentocchini, 2015).

The second premise concerns the definition of green jobs. While there is an open debate on where the boundaries of this subset lie (see i.e., Deschênes, O., 2013; and Vona, Marin and Consoli, 2017), scholars and policy experts concur that the greening of modern economies is a gradual process characterised by the progressive take up of routines designed to deal with new or revised criteria of environmental sustainability. As such, greening of the economy is expected to affect the entire workforce, though with varying degree. To address the multiple 
labour market effects induced by environmental sustainability we rely on an official repository of occupations compiled by the US Bureau of Labour Statistics that contemplates a broad spectrum of scenarios including the emergence of new jobs, the qualitative transformation in the work content of existing jobs as well as the increase in demand for jobs that carry out work tasks that are not bespoke, but complementary to, green activities.

The third proviso is that exploring the regional determinants of green employment entails a thorough assessment of how the existing industrial and institutional settings shape the environment in which green activities emerge. Previous literature in economic geography calls attention to knowledge spillovers as a precondition for the diffusion of new activities (Glaeser, Kallal, Schinkmann and Shleifer, 1992). It also argues that because of the tacit nature of knowledge in early stages of major transitions - and the shift to low-carbon economies is understood to be at early stage (see review by Barbieri, Ghisetti, Gilli, Marin \& Nicolli, 2016) - repeated interactions between agents are most effective within delimited geographical and cognitive spaces. But, on the other hand, whether and how much spillovers are a catalyst for structural change depends on the type of complementarity that binds together key change actors in a region (Iammarino and McCann, 2006). Our point of departure is the tenet that the industrial setting of a region exhibits different forms of diversity, namely related and unrelated variety (see the seminal study by Frenken, Van Oort and Verburg, 2007 and a review of empirical studies by Content and Frenken, 2016).

Bringing together the threads outlined above, the key question is: what can an assessment of regional economic variety elucidate on the greening of employment? According to the OECD (2011), achieving green growth entails catalysing investments and innovation to foster economic growth and development while ensuring efficient use of natural resources. 
However, the transition to the new model will draw from a variety of domains in a recombinant fashion, and local sectoral composition will likely affect the rate and direction of this process. Crucially, both the transfer of know-how and the development of new shared routines will depend on the degree of cognitive proximity across sectors.

This paper operationalises these ideas by studying the role of regional variety in the growth of green employment. Previous literature has put forth the distinction between related variety - viz. within-industry diversity due to connection among activities that share similar resource bases - and unrelated variety - viz. between-industry diversity, which instead calls upon spanning a wider spectrum of different, possibly not hitherto connected, capabilities (Boschma and Frenken, 2011; Boschma, 2017). Diversification stemming from related variety confronts lower costs and uncertainty compared to diversification that thrives on new connections in the space of regional activities. We argue that both these dimensions are relevant to the context under analysis. A recent study by Castaldi, Frenken and Los (2015) lends support to our conjecture. Therein, related variety and unrelated variety are found to be complementary for innovation, and contingent upon life-cycle type of dynamics. In particular, related variety concerns innovations that develop incrementally out of established cognitive structures across connected domains while unrelated variety, though more uncertain and initially costly, can be a catalyst for breakthroughs that span, by necessity or by design, new functionalities. On these grounds Castaldi et al (2015) conclude that unrelated variety paves the way to frontier activities that will become more related as they transition through stages of the life cycle.

Connecting this thread to the main topic of this paper, we propose that the tension between old and new, and the complexity of the costs and benefits entailed by pursuing novelty or 
maintaining the status quo resonate with the reality of transitioning towards sustainability. The path towards green growth is not a sketch on a blank canvas: existing productive structures rely on prior bounds between resource availability and models of extraction and transformation, and achieving green growth entails dismantling pre-existing structures as well as designing and implementing new ones. This applies to business firms, technologies, institutions and, at a more fundamental level, to the dynamics of the skills' base (Vona and Consoli, 2015). How such a process plays out, however, depends on whether and to what extent relatedness among existing activities impedes or enables the transition to low-carbon local economies.

The present paper contributes to previous literature in various ways. First, it explores whether and to what extent related and/or unrelated variety contribute to local growth of green jobs in US MSAs between 2006 and 2014. To the best of our knowledge this is the first paper to analyse a policy relevant issue such as the greening of our economies through the lenses of regional economic variety. Further, akin to Wixe and Andersson (2017) we move beyond the traditional remit of prior analyses based solely on industry classifications and include measures of regional variety based on occupations. Lastly, we add to previous research by assessing the impact of related and unrelated variety across different categories of jobs identified through their skill content.

The main findings of our study are two. First, unrelated variety at industry level is a positive and significant predictor of green employment. An increase of one standard deviation in unrelated variety is associated with an increase of green employment share growth between $0.3 \%$ and $1.1 \%$. This is robust to the inclusion of various controls and over different time spans. Tellingly, related variety has little to no effect. The latter is in line with a small but 
growing (see Boschma, 2017) stream of studies that focus on the characteristics of and the enabling conditions for unrelated variety (e.g. Crespo, Suire and Vicente, 2014; Castaldi et al, 2015; Xiao, Boschma and Andersson, 2016). The second key finding concerns the differential effect of regional diversification across occupational categories: while unrelated variety at industry level favours the growth of mid- to low-skill jobs, unrelated variety at occupational level favours high- to mid-skill jobs. In particular, a one standard deviation increase of unrelated variety at the occupational level yields a $1.1 \%$ increase of green employment share growth among non-routine interactive occupations and a $0.4 \%$ increase in the growth rate in routine cognitive occupations. Conversely, an increment in unrelated variety at the industry level accelerates green employment share growth in non-routine and routine manual by about $0.2 \%$ and $0.4 \%$, respectively.

The remainder of the paper is organised as follows. Section 2 provides an overview of the data and variable construction. Section 3 presents the empirical analysis. The last section concludes and summarises.

\section{Research Design}

This section begins by detailing the main data sources, namely the 'Green Economy' of the Occupational Information Network (O*NET), Occupation Employment Statistics (Source: US Bureau of Labor Statistics) and County Business Patterns (Source: US Census Bureau). Subsequently, we describe variable construction.

\section{Dependent variable}

To construct the database on green employment we combine the methodologies of previous studies, namely Consoli, Marin, Marzucchi and Vona (2016) and Vona et al (2017). The 
main data source is the 'Green Economy' programme of O*NET which consist of a comprehensive list of occupational categories that are affected by the greening of the economy. ${ }^{1}$ This database is designed to account for multiple labour market outcomes. At one end of the spectrum are 'Green New \& Emerging' jobs that carry a specific environmental orientation. Examples of this type of jobs would be 'Biofuels Production Managers' (SOC 11-3051.03) or Energy Brokers (SOC 41-3099.01). Another possible outcome is the qualitative transformation in the work content of existing jobs to accommodate growing demand for environmental criteria. Instances of these 'Green Enhanced Skills' jobs are 'Soil and Water Conservationists' (SOC 19-1031.01), 'Architectural and Engineering Managers' (SOC 11-9041.00). Yet another circumstance contemplated by O*-NET is that of jobs that, in spite of not performing bespoke environmental-related activities, are in growing demand because their main work tasks are of a general, yet complementary to green, nature. 'Industrial Production Managers' (SOC 11-3051.00), ‘Chemical Engineers’ (SOC 172041.00) are good cases in point of these 'Green Increased Demand' occupations. To analyse variation over time and space, $\mathrm{O}$ NET data on green jobs are matched with employment data by occupation for 367 US Metropolitan Areas over the period 2006-2014 (Source: Occupation Employment Statistics, US Bureau of Labor Statistics - BLS henceforth). Such a procedure entails addressing a mismatch between BLS employment, available at 6-digit SOC level, and O*NET information on green occupations, available at 8digit SOC. To deal with this issue we follow Consoli et al. (2016) and assume a uniform distribution of 8-digit occupations within the same 6-digit occupation. That is,

\footnotetext{
${ }^{1}$ https://www.onetcenter.org/dictionary/21.3/excel/green_occupations.html The methodology is laid out in detail in Dierdoff et al (2009).
} 


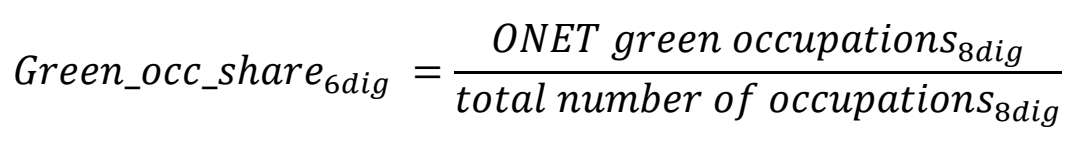

where Green_occ_share is the share of green employment of each 6-digit occupation that ranges from 0 , when all 8-digit occupations within the 6-digit occupation are non-green, and 1, when all 8-digit occupations within the 6-digit occupation are ONET green occupations. Between the two bounds are all 6-digit occupations with both green and non-green 8-digit occupations. ${ }^{2}$ Following Vona et al (2017) we then compute a spatial measure of green employment share (GES) as follows:

$G E S_{i t}=\sum_{k}$ Green_occ_share $* \frac{L_{k i t}}{L_{i t}}$

where $L_{k i j}$ is the employment in occupation $k$, US Metropolitan Area (US MA) $i$ at time $t$. It is noteworthy that $G E S$ variation across US MAs and over time depends entirely on differences in the labour force at the local level since Green_occ_share is at the level of occupation and does not vary over time.

The national share of green jobs in our sample of 841 6-digit SOC occupations is about 20\%. ${ }^{3}$ Figure 1 shows their distribution across all major occupational groups (2-digit SOC).

\footnotetext{
2 To illustrate: 'Advertising and Promotions Managers' (11-2011.00) and 'Green Marketers' (11-2011.01) are classified in the same SOC 6-digit code, 11-2011. Since the 6-digit code 11-2011 includes no other occupations, and since 'Green Marketers' is a green occupation in O*NET, we assume that workers are equally distributed across the two 8-digit occupations, each with a 0.5 Green_occ_share. For robustness tests and further details of this method, see Consoli et al (2016).

${ }^{3}$ An important caveat is that our analysis is based on the full sample of green occupations available in O*NET. Other studies use a different selection: Consoli et al (2016) leave the Green Increased Demand group out of
} 
The first feature that stands out is that only 14 out of 22 macro categories include green occupations. Second, six of these categories account for $75 \%$ of green employment. These encompass an ample spectrum ranging from high-skill Management jobs [SOC 11] $(2.5 \%$ employment share) to mid-skill occupations like Transportation \& Material Moving [SOC 53] (3.5\%), Production [SOC 51] (2.8\%) and Office \& Administrative Support [SOC 43] $(1.8 \%)$. Green jobs are also present in two low-skill jobs categories: Construction \& Extraction [SOC 47] (2.5\%) and Installation, Maintenance and Repair [SOC 49] (2.2\%). Looking within occupational macro-groups we observe that the lion share of green employment is made up of existing jobs. Indeed, 'Green New and Emerging' jobs are the smaller category, and are most prominently featured among high-skill occupational groups like Management, Architecture \& Engineering, Business \& Financial Operators and Sales. Conversely, 'Green Increased Demand' jobs are overrepresented among mid-skills occupations, especially Transportation and Material Moving, Production and Office \& Administrative Support. Low-skill occupational categories exhibit a more balanced profile with almost equal shares of 'Green Increased Demand' and 'Green Enhanced Skills' jobs.

\section{FIGURE ONE ABOUT HERE}

The indications stemming from the analysis of the aggregate green workforce can be further qualified by focusing on functional categories of occupations. To do this, we rely on the methodology proposed by Autor et al. (2003) wherein occupations are grouped on the basis on their task content and of the associated skill profiles. In this framework, known as the task-based model, occupations are classified along two dimensions: ‘cognitive' versus

their analysis while Vona et al (2017) use O*NET data on skills to build an entirely novel measure of green employment. As a result, figures concerning the relative magnitude of the green economy tend to differ across these studies. We think that these differences can be reconciled in light of the still open nature of the debate on green employment. 
'manual' jobs, and 'routine' versus 'non-routine' jobs. Non-routine cognitive occupations involve a great deal of mental flexibility, creativity, problem-solving and personal interaction such as managerial, professional and technical workers. Routine cognitive occupations are those that entail tasks that can be summarized in rule-based instructions, like jobs in sales or office and administrative support. Routine manual occupations are "blue collar" jobs mostly involving the execution of repetitive physical procedures, for example assemblers or construction. Lastly, non-routine manual occupations are service jobs, that is, activities involving physical dexterity and adaptability as well as human interaction. To assign occupations on the basis of their task content, we use data from the O*NET Work Activities and Work Context. This is a repository of information on the importance scales the work tasks for all SOC occupations. ${ }^{4}$ Following the procedure by Acemoglu and Autor (2011) we collapsed these scores into SOC occupations, ranked them accordingly and assigned the top $30 \%$ occupations in the list to each of the five skill groups. Finally, the green employment share of each group was computed. Such a methodology enables us to identify occupations with the highest score in each of the skill categories.

\section{Independent variables}

As the paper aims to identify the effects of diversification in the knowledge base and organisation of work across US MAs on green employment share growth, our key explanatory variables are calculated using employment by industry and employment by occupation statistics from the US County Business Patterns survey. The common method employed to calculate diversification is the entropy approach (Jacquemin and Berry, 1979;

\footnotetext{
${ }^{4}$ See Data Appendix in Acemoglu and Autor (2011) for the list of task items assigned to each skill group. O*NET reports each task item on a 1-to-5 scale that measures the intensity of the task in O*NET-SOC occupations. Normalisation of the raw averages of each score was performed to have mean zero and standard deviation one.
} 
Attaran, 1986). This measure can be decomposed at different digit levels of the hierarchical structure of the data (Frenken et al., 2007) and takes into account both absolute and relative abundance of groups in this structure (Wixe and Andersson, 2017). We calculated related and unrelated variety to capture within and between diversity across industries and occupations using, respectively, employment data at two and four digits of the North American Industry Classification System (NAICS) and the SOC.

Following Frenken et al. (2007), let each four-digit sector i be exclusively part of a two-digit sector $S_{g}$, where $g=1, \ldots, G$. The two-digit shares of employment $P_{g}$ can be obtained by summing the five-digit shares $\mathrm{p}_{\mathrm{i}}$ :

$$
\mathrm{P}_{\mathrm{g}}=\sum_{\mathrm{i} \in \mathrm{S}_{\mathrm{g}}} \mathrm{p}_{\mathrm{i}}
$$

Unrelated variety is measured as follows:

$$
\mathrm{UV}=\sum_{\mathrm{g}=1}^{\mathrm{G}} \mathrm{P}_{\mathrm{g}} \log _{2}\left(\frac{1}{\mathrm{P}_{\mathrm{g}}}\right)
$$

whereas related variety is computed as:

$$
R V=\sum_{g=1}^{G} P_{g} H_{g}
$$

where:

$$
\mathrm{H}_{\mathrm{g}}=\sum_{\mathrm{i} \in \mathrm{S}_{\mathrm{g}}} \frac{\mathrm{p}_{\mathrm{i}}}{\mathrm{P}_{\mathrm{g}}} \log _{2}\left(\frac{1}{\mathrm{p}_{\mathrm{i}} / \mathrm{P}_{\mathrm{g}}}\right)
$$

\section{Empirical strategy}


The estimated model takes the following form:

$$
\Delta G E S_{M A, t}=\alpha+\beta_{1} U V_{M A, t}+\beta_{2} R V_{M A, t}+\beta_{3} \text { Controls }_{M A, t}+\gamma_{M A}+\delta_{t}+\varepsilon_{M A, t}
$$

where $\triangle G E S$ is the average log-difference of green employment share in US $M A$ s for the periods 2006-2009 and 2010-2014. Furthermore, we run the model using green employment in occupations characterised by a higher share of non-routine cognitive, non-routine interactive, non-routine manual, routine cognitive and routine manual tasks (Autor et al. 2003). $U V$ and $R V$ are the explanatory variables of main interest calculated at the beginning of each period and included as standardised scores (with zero mean and standard deviation of one) in order to ease the interpretation of the coefficients since RV and UV do not have a natural scale or metric. Controls refers to a set of log-transformed controls which capture potential drivers of green employment share growth other than UV and RV. In particular, we include employment in manufacturing, year of schooling and per capita income for each MA. Finally, $\gamma_{M A}$ is a set of local dummies, $\delta_{t}$ a time dummy variable and $\varepsilon_{M A, t}$ the error term. Each regression is weighted by population and the parameters are estimated using Ordinary Least Squares (OLS) with standard errors clustered at the US Federal State level.

\section{Results}

This section contains descriptive statistics in the first part and the results of the regression analysis in the second.

\section{Descriptive analysis}


Before turning to the results of the regression analysis, it is useful to provide an overview of the empirical characteristics of the key dimensions at hand. Table 1 contains these descriptive statistics computed over all 367 MSAs. Figures 2 and 3 show the geographical distribution of green employment shares, Related and Unrelated Variety over MAs. Therein state boundaries are outlined in grey and the interior of each area is shaded according to its decile rank in the distribution of the relevant dimension. Colour coding is darker for higher deciles and progressively lighter for lower ones.

\section{TABLE ONE ABOUT HERE}

As mentioned above, the mean green employment share (GES) in the US is about $20 \%$. Over time it declines by about $2 \%$ between 2006 and 2009 - coinciding with the onset of the global financial crisis - and grows by $1 \%$ in the period 2010-2014. MAs in the top decile of GES account for about $27 \%$ of overall green employment over the period under analysis. This cluster exhibits some degree of persistence, as about $50 \%$ of areas stay in the top $10 \%$ both in 2006 and in 2014. Compared to the bottom 90\%, areas in the top decile exhibit greater loss of GES by $2010(+4 \%)$ and greater growth by $2014(+11 \%)$. Looking at the geographical distribution, top GES areas both in 2006 and in 2014 are mostly in the righthand side quadrant coinciding with the territories of the Midwest, the South and the Northeast (Fig. 2). A notable feature is that throughout the period the cluster of top GES areas includes mostly second-tier cities, with the exception of Detroit, Houston and Memphis. Indeed, the mean density of MAs in the top $10 \%$ of GES is $40 \%$ lower than all the remaining ones in 2006 (25\% in 2014).

\section{FIGURE TWO ABOUT HERE}

Next, we explore the distribution of sectoral diversification as captured by means of Related 
and Unrelated Variety. Recall that according to Frenken et al. (2007) RV, entropy at fourdigit level, captures variety within each of the two-digit sectors in an area, i.e. diversification across sub-sectors that share similar know-how. By contrast, UV - or entropy at two-digit industry level - measures the extent of diversification of activities carried out within a MA. The latter relies on complementarities of different knowledge bases within a region, and for this is considered strategically important to mitigate the risk of mass unemployment, especially during a downturn (Frenken et al, 2007).

Unrelated Variety remained constant around a mean value of 3.90 over the period under analysis. The cluster of top decile by UV exhibits a high degree of persistence, with about $70 \%$ of MAs in the top $10 \%$ both in 2006 and in 2014. In general, UV is found to be higher in the metropolitan areas of mid-tier cities such as Charlotte, Portland, Denver and Kansas City. With the exception of Los Angeles, Dallas, Houston, Atlanta and Seattle, most of the largest US cities do not rank high in unrelated diversification. The diagram also shows that UV is on average higher in the right-hand side portion of the map, and thus in the territories of territories of the Midwest, the South and the Northeast (Upper panel, Fig. 3). MAs in the top decile of UV account for about $22 \%$ of green employment in 2006 (21.4\% in 2014). Lastly, while the decline of overall GES in the period 2006-2010 was 5\% higher in the top UV decile relative to the remaining areas, by 2014 GES growth was $28 \%$ higher in MAs in the top decile. These observations lead to expect that the change of GES is correlated with initial levels of unrelated variety.

Turning to the other measure of diversification, Related Variety is on average lower than UV, with a mean oscillating around 2.6 in the period under analysis. The degree of persistence in the top decile of RV is $68 \%$, somewhat lower than that of UV. Areas in the top 
decile of RV are about $70 \%$ more dense compared to the rest. Indeed, different from what was observed in the case of UV, the vast majority of US larger and denser cities are concentrated in the top $10 \%$ (i.e., Los Angeles, Chicago, Philadelphia, Cleveland, New York, Pittsburgh, Miami). Still in the top decile are mid-tier large areas like Providence, New Haven, Buffalo, Milwaukee. This cluster of areas accounts for a mean share of green employment of about 19\%, slightly below that of all the remaining MAs (20\%). Also, their mean growth of GES is only $10 \%$ higher than that of all other areas. As the lower panel of Figure 3 shows, RV is more concentrated on the two coasts and the Midwest. All in all, these descriptive statistics do not hint at a strong correlation between GES and RV.

\section{FIGURES TWO AND THREE ABOUT HERE}

\section{Regression analysis}

Table 3 shows the results of the model estimation using total green employment share growth at the MA level as dependent variable. The coefficient of UV is statistically significant and robust across different specifications. This is a first insight into a positive relationship between diversification of the industrial structure at high digit level (2-digit NAICS) and green employment share growth. Indeed, diversification across unrelated sectors is associated with an increase in the share of green employees relative to non-green, holding other variables constant. Our favourite specification in Column 1 reveals that an increase of one standard deviation in UV is correlated with an increase of $0.3 \%$ in average growth of green employment share over the subsequent 4 years. ${ }^{5}$ The result holds when UV is calculated using the number of establishments instead of the number of employees

\footnotetext{
${ }^{5}$ Since collinearity may inflate the variance of regression coefficients, we calculated the variance inflation factors (VIF). The VIF of each independent variable is below the threshold value of five, with a mean value of 2.22, suggesting collinearity does not affect our results.
} 
(Column 2). In addition, Column 3 shows that if we calculate green employment share growth over a longer period (2006-2014) and use it as dependent variable, an increase of one standard deviation in UV is associated with an increase in green employment share growth of $0.4 \%$. Finally, when the dependent variable is measured using the log-difference of green employment share between the first and final year of each period (i.e. 2006-2009 and 20102014) instead of the average growth rate (Column 4), the coefficient of UV reaches its maximum across the five specifications. A one standard deviation increase in UV leads to $1.2 \%$ growth of green employment share.

\section{TABLE THREE ABOUT HERE}

This result confirms that green employment share growth, which is one of the ways in which the transition to green economies manifests itself, is correlated with diversification across sectors (in the sense of connecting industries that are otherwise unrelated). Moreover, while unrelated variety plays a pivotal role, related variety seems to be ineffective in the transition towards environmentally-sustainable economy. At a first glance, this may seem in contradiction with studies showing that relatedness is a crucial driver of employment growth. However, it is noteworthy engaging green activities entails a closer focus on skills and human capital that differ from those used by non-green jobs (Consoli et al., 2016). In addition, to capture the relationship between variety and the greening of the economy, our paper focuses on the correlation between diversification and the share of green workers within regions rather than the number of employees. In the transition towards low-carbon economy, regions that diversify their industrial structure across unconnected industries and, therefore, broaden their knowledge space, are more likely to spur the recombination process that underlies the early phases of radical change (Castaldi et al. 2015). 
To assess whether industrial diversification favours any particular group of green jobs, we run our baseline model by distinguishing workers following the task-based framework (Autor et al, 2003; Acemoglu and Autor, 2011). Therein, occupations are grouped according to the intensity of the task content of each two-digit occupation. The coefficient of UV is strongly positive and significant for occupations with higher intensity of routine and nonroutine manual tasks, both low-skill categories (Table 4). To a less extent, RV is positive and mildly significant $(\mathrm{p}$-value $<0.10)$ for high-skill non-routine interactive occupations.

Lastly, following Wixe and Andersson (2017), we add to the analysis two coefficients for related and unrelated variety at the occupation level (Table 5). As noted before, the coefficient of UV at industrial level in non-routine and routine manual task occupations is still positive and significant. On the other hand, UV is positive and significant for nonroutine interactive and routine cognitive occupations. This offers insights into the importance of diversification across different occupations to boost green employment share growth for occupations that requires high intensity of interactive skills, such as Management, Business and Financial, Computer and Mathematical, or Architecture and Engineering occupations, and cognitive skills mainly needed in occupations such as Legal, Healthcare Practitioners and Technical, or Protective Service. The finding suggests that the interplay of cognitive distant knowledge bases can favour problem solving associated with the disruptions brought about by the new paradigm of environmental sustainability. Key to this passage is that the skills used in these occupations have strong cognitive content, which in turn suggests that local economies need both creativity for change as well as analytical and managerial abilities to minimise the uncertainty involved with the transition to green growth.

TABLE FOUR AND FIVE ABOUT HERE 


\section{Concluding remarks and the way ahead}

This paper has explored the issue of whether and to what extent the organization of local activities influences the transition towards environmentally sustainable economies. This question was operationalized by using the growth of green employment share as dependent variable and regional related and unrelated variety as the main explanatory variables in a regression analysis on 367 US metropolitan areas over a nine-year period. The main finding is that unrelated diversification is positively related to the growth of green employment. On the other hand, related variety does not yield significant effects in any of the baseline specifications. Read in conjunction with the indications of the descriptive statistics, green employment growth appears to be relatively stronger where UV is higher, namely in the metro areas of medium-sized cities rather than in the largest cities. Further, estimates by occupational groups reveals that related variety is significant only for high-skill jobs that entail more intensive use of non-routine intensive capabilities, such as negotiation or team training. These estimates also indicate the positive effect of unrelated variety on the employment share growth of green mid- to low-skill occupations, namely non-routine manual and routine jobs. Results are robust to the use of alternative measures of variety, namely number of establishments by sector and occupational categories.

We believe that the connection between regional diversification and the transition to environmentally sustainable economies can enrich ongoing scholarly and policy debates. When it comes to greening of the economy the broader question is how regions develop new growth paths, and why they differ in their ability to do so. In the economic geography literature such a question is framed in terms whether and to what extent locally related activities can act as an enabling factor in the search for these paths. By and large, empirical 
works corroborate the hypothesis that relatedness is an important driver of regional diversification across a broad spectrum of dimensions (e.g., products, industries, technologies) and of spatial units (e.g., countries, regions, cities, labour market areas) of analysis (see reviews by Content and Frenken, 2016). The common finding in this stream of research is that related diversification is a stronger driver compared to unrelated diversification. This is, to some extent, not surprising considering the nature of both constructs. As Boschma (2017) puts it, diversification is an uncertain process that can be better dealt with by relying on available local resources, and on well-tested connections across them, both trademark features of related variety. Unrelated diversification, on the other hand, entails implementing new forms of coordination across different and formerly unassociated capabilities (Desrochers and Leppälä, 2011). As Castaldi et al. (2015) argue, however, the two forms of regional diversification need not be seen as opposites in a static fashion but rather as complementary forms of organising and creating resources in a dynamic process.

Our results fit into this framework by reinforcing the conjecture that the transition towards environmentally sustainable production is still at early stages. No doubt, this complex process entails adaptations at many levels, not just within firms and industries but, ultimately, in the attendant cognitive and organizational dimensions. We focus on changes in the labour force under the belief that employment is the vehicle through which human knowhow is applied to economic activities (Consoli and Rentocchini, 2015) and that, therefore, this is a useful empirical dimension to keep track of how, in this particular instance, local economies transform their routines to accommodate new criteria for environmental sustainability. At this early stage of the transition towards greener economies, the scope of 
the adaptations that need be made is still open to negotiation, and its costs and benefits are not totally understood. Thus, the room for trial and error is bigger, and so is the need to tap into different pools of knowledge. This is the part of the process where unrelated variety is more potent vehicle, in spite of the possible shortcomings due to experimenting and failing with untried combinations. If this logic holds, as the scope of the adaptation narrows, and stable routines emerge, recombining closely related knowledge should become a more viable strategy in the future. As already hinted at in the introduction, the path towards green growth does not happen in vacuum but, rather, on top of existing systems for extracting and transforming resources. This will entail partly dismantling pre-existing structures and partly setting up new ones. The present paper reinforces the claim that underneath the visible changes that this transition will ignite in technology, institutions and business firms is the evolution of the knowledge base and, thus, the relevant skills as well as the forms of organizing workers' know-how (Vona and Consoli, 2015).

A full discussion of the policy implications that can be derived from these findings is beyond the scope of the current paper. Further research is needed to probe the validity of the findings about the effects of related variety and unrelated variety on the green employment. This is crucial to inform policy, and can be done by exploring different avenues. First, our methodology could be replicated in the context of countries other than the US. Differences in institutional settings and in historical contingencies will surely enrich the panel of empirical results and further elucidate on the nature and extent of green employment. Second, the analysis could be extended to explore the effect of 'green knowledge' endowment and innovation. Investments in research and development in the domain of environmental sustainability are growing fast, and various forms of innovation are already visible in the 
horizon. Understanding the extent to which specialization or diversification favour or hamper green local innovation capacity would contribute a great deal to the formulation of policy. Third, the effects of variety could be analysed at different levels of geographical aggregation. Moving beyond metropolitan statistical areas, one could resort to alternative spatial constructs, for example travel-to-work areas that are constructed by calibrating economic and social characteristics of geographical areas so as to increase the potential for policy impact. These are but a few possible avenues in which research on regional diversification and on environmental sustainability can enrich each other. We hope that the present paper has provided enough insights to start such an exciting research agenda.

\section{Acknowledgements}

We wish to thank Carolina Castaldi, Tommaso Ciarli, Koen Frenken, Alberto Marzucchi, Francesco Rentocchini, Maria Savona and Ariel Wirkierman for useful comments on an earlier draft. We also thank participants at SPRU 50th Conference (Univ. of Sussex, Brighton), at the 4th Doctoral Workshop in Economics of Innovation, Complexity and Knowledge (BRICKS, Collegio Carlo Alberto, Turin) and at SPRU seminar series. Davide

Consoli acknowledges the financial support of the Spanish Ministerio de Economia y Competitividad (RYC-2011-07888). Nicolò Barbieri has received financial support from the European Commission Horizon 2020 project titled 'European Global Transition Network on Eco-Innovation, Green Economy and Sustainable Development (green.eu)' (Grant Agreement: 641974). 


\section{References}

Acemoglu D. \& Autor D. (2011). Skills, tasks and technologies: Implications for employment and earnings. Handbook of labor economics, 4, 1043-1171.

Attaran, M. (1986). Industrial diversity and economic performance in US areas. The Annals of Regional Science, 20(2), 44-54.

Autor D., Levy F. \& Murnane R.J. (2003). The skill content of recent technological change: An empirical exploration. Quarterly Journal of Economics, 118(4), 1279-1333.

Barbieri, N., Ghisetti, C., Gilli, M., Marin, G., \& Nicolli, F. (2016). A survey of the literature on environmental innovation based on main path analysis. Journal of Economic Surveys, 30(3), 596-623.

Boschma R. \& Frenken K. (2011). Technological relatedness and regional branching. In H. Bathelt, M. P. Feldman and D.F. Kogler (Eds.): Beyond territory. Dynamic geographies of knowledge creation, diffusion and innovation (pp. 64-81). London: Routledge.

Boschma R. (2017). Relatedness as driver of regional diversification: a research agenda. Regional Studies, 51(3), 351-364.

Castaldi C., Frenken K. \& Los B. (2015). Related variety, unrelated variety and technological breakthroughs: an analysis of US state-level patenting. Regional studies, 49(5), 767-781.

Consoli, D. \& Rentocchini, F. (2015). A taxonomy of multi-industry labour force skills. Research Policy, 44(5), 1116-1132.

Consoli D., Marin G., Marzucchi A. \& Vona F. (2016). Do green jobs differ from non-green jobs in terms of skills and human capital?. Research Policy, 45(5), 1046-1060.

Content J. \&Frenken K. (2016). Related variety and economic development: a literature review. European Planning Studies, 24 (12), 2097-2112.

Crespo, J., Suire R., \& Vicente J. (2014). Lock-in or lock-out? How structural properties of knowledge networks affect regional resili- ence. Journal of Economic Geography, 14, 199-219.

Deschênes, O., (2013). Green jobs, Policy Paper No. 62. Bonn: Institute for the Study of Labor.

Desrochers, P. \& Leppälä, S. (2011). Opening up the 'Jacobs spillovers' black box: local diversity, creativity and the processes underlying new combinations, Journal of Economic Geography 11, 843-863.

Dierdorff E.C., Norton J.J., Drewes D.W., Kroustalis C.M., Rivkin D. \& Lewis P. (2009). Greening of the World of Work: Implications for O*NET-SOC and Newand Emerging Occupations. Report prepared for U.S. Department of Labor,Employment and Training Administration, Office of Workforce Investment,Division of Workforce System Support, Washington, DC. 
Frenken K., Van Oort F. \&Verburg T. (2007). Related variety, unrelated variety and regional economic growth. Regional studies, 41(5), 685-697.

Glaeser E.L., Kallal H.D., Schinkmann J.A. \&Shleifer A. (1992) Growth in cities. Journal of Political Economy 100: 1126-1152.

Iammarino S. \& McCann P. (2006) The structure and evolution of industrial clusters transactions, technology and knowledge spillovers. Research Policy 35, 1018-1036.

Jacquemin A.P. \& Berry C.H. (1979). Entropy measure of diversification and corporate growth. The Journal of Industrial Economics, 359-369.

Organization for Economic Co-operation and Development [OECD] (2011). Towards Green Growth: Monitoring Progress. Paris: OECD http://www.oecd.org/greengrowth/48224574.pdf

Vona, F. \& Consoli, D. (2015). Innovation and Skill Dynamics: a life-cycle approach. Industrial and Corporate Change 24(6): 1393-1415.

Vona F., Marin G. \& Consoli D. (2017). Measures, Drivers and Effects of Green Employment: Evidence from US Local Labor Markets, 2006-2014. SPRU Working Paper Series 07/17.

Xiao, J., Boschma, R., \& Andersson, M. (2016). Industrial diversification in Europe: The differentiated role of relatedness (Papers in Evolutionary Economic Geography No. 16.27). Utrecht: Utrecht University.

Wixe S. \& Andersson M. (2017). Which types of relatedness matter in regional growth? Industry, occupation and education. Regional studies, 51(4), 523-536. 


\section{Figures}

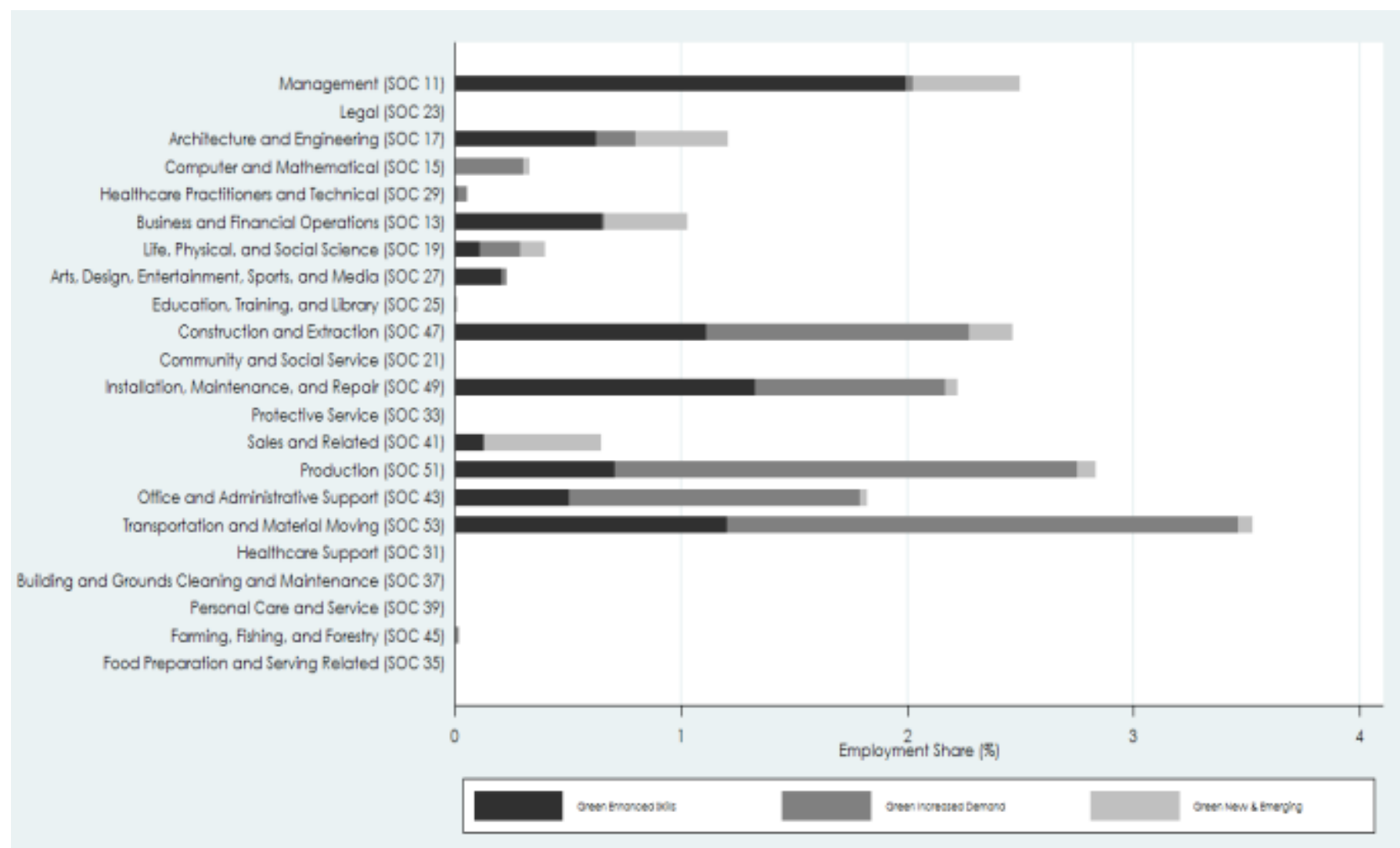

Figure 1. Green employment share across 2-digit SOC codes (2014) 

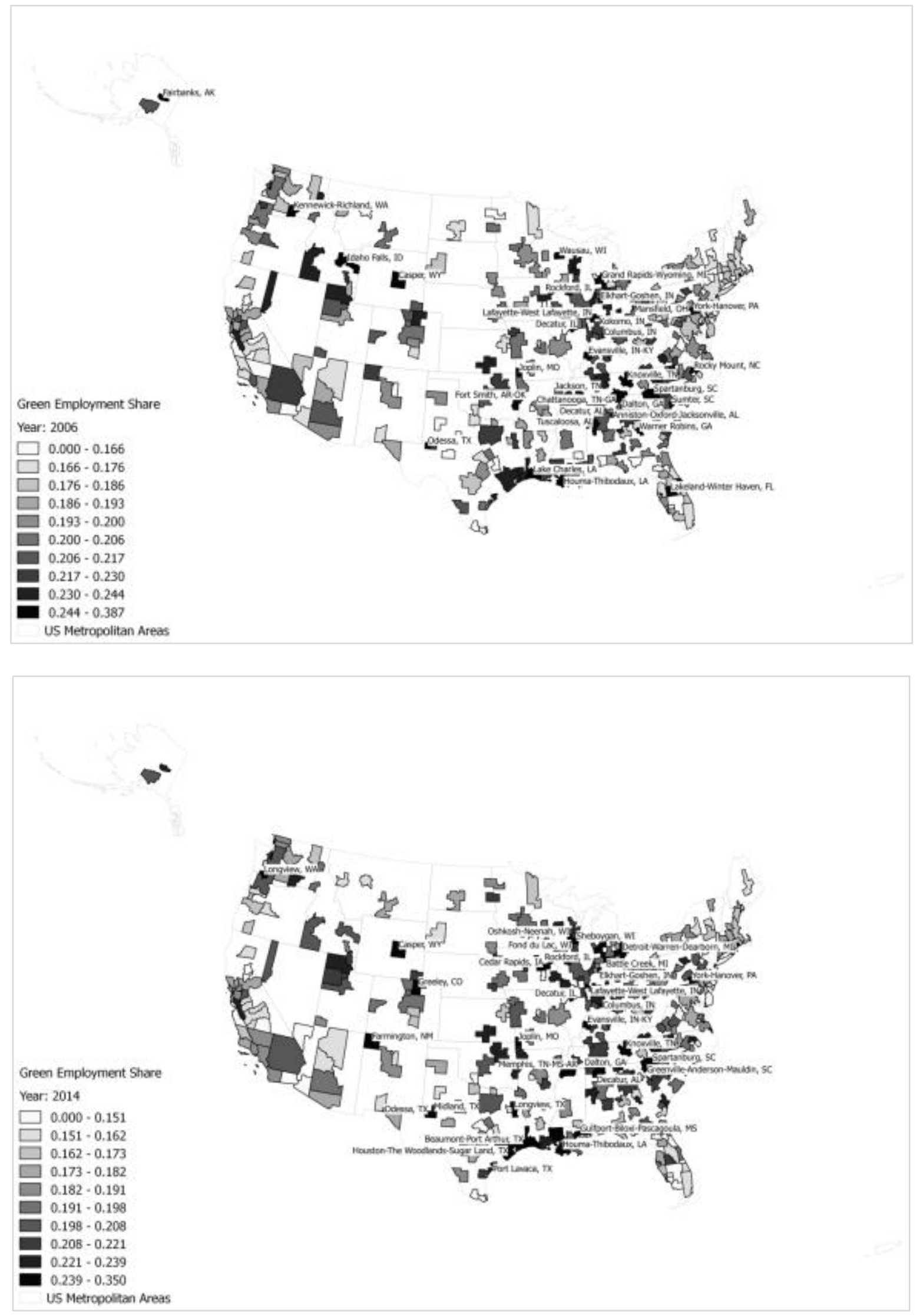

Figure 2. Geographical distribution of Green Employment Share, 2006-2014 


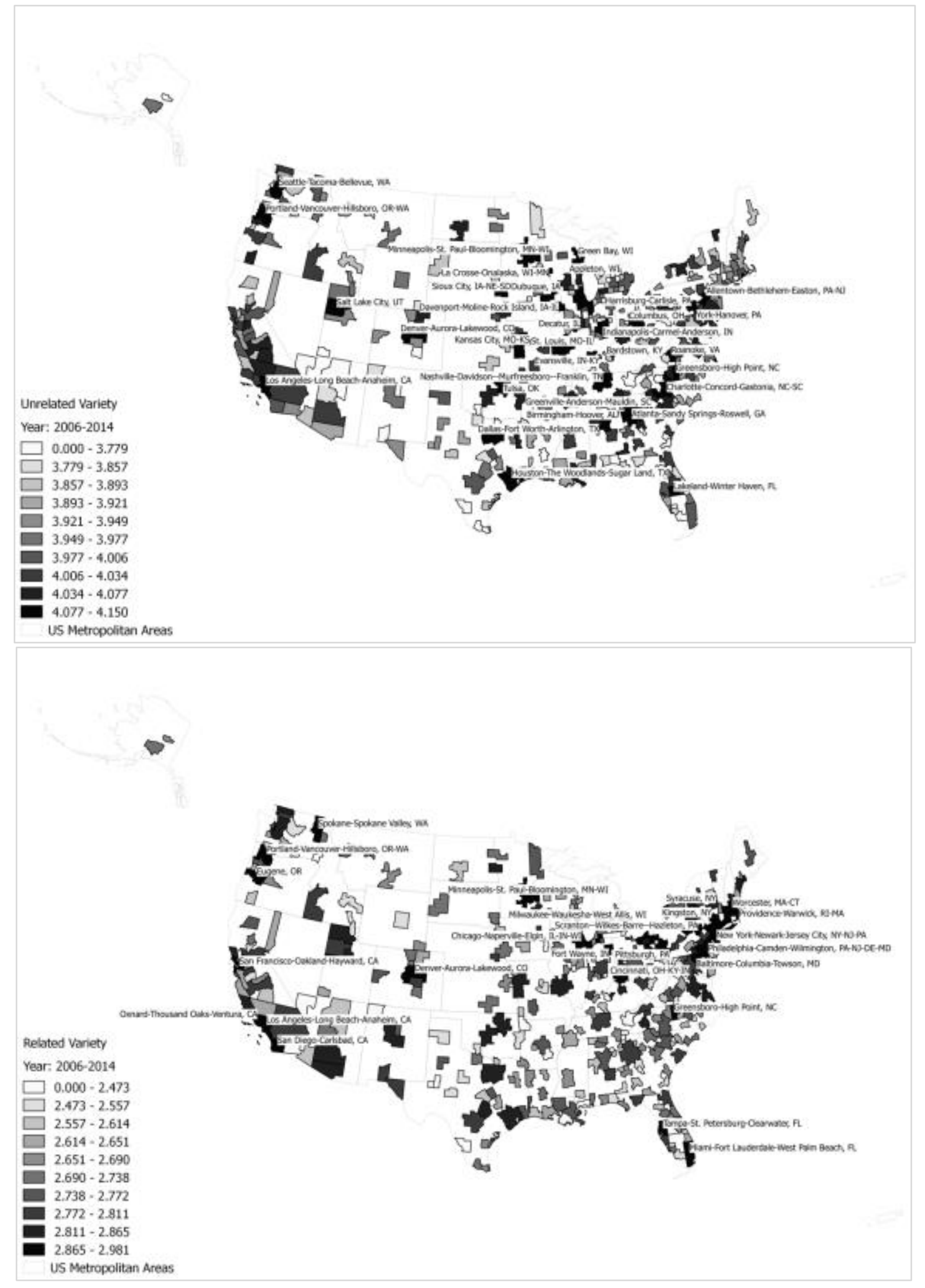

Figure 3. Geographic distribution of Unelated (Upper panel) and Related Variety (Lower panel) 


\section{Tables}

\begin{tabular}{|c|c|c|c|c|c|c|}
\hline Variable & Description & Obs & Mean & St Dev & Min & $\operatorname{Max}$ \\
\hline \multicolumn{7}{|c|}{ Growth in green employment share } \\
\hline$\Delta \mathrm{GES}$ & All occupations & 367 & -0.007 & 0.024 & -0.096 & 0.069 \\
\hline$\Delta$ GES_NRC & Non-routine cognitive occupations & 367 & -0.004 & 0.044 & -0.212 & 0.207 \\
\hline$\Delta$ GES_NR & Non-routine interactive occupations & 367 & -0.005 & 0.053 & -0.673 & 0.237 \\
\hline$\Delta \mathrm{GES} \_\mathrm{NRM}$ & Non-routine manual occupations & 367 & -0.002 & 0.018 & -0.061 & 0.069 \\
\hline$\Delta$ GES_RC & Routine cognitive occupations & 367 & -0.005 & 0.042 & -0.243 & 0.198 \\
\hline$\Delta$ GES_RM & Routine manual occupations & 367 & -0.006 & 0.021 & -0.094 & 0.077 \\
\hline \multicolumn{7}{|c|}{ Related Variety } \\
\hline RV_IND & Employment by industry & 367 & 2.668 & 0.166 & 1.786 & 3.013 \\
\hline RV_EST & Number of establishment by industry & 367 & 2.847 & 0.069 & 2.498 & 2.984 \\
\hline RV_OCC & Employment by occupation & 367 & 3.711 & 0.148 & 3.177 & 4.044 \\
\hline \multicolumn{7}{|c|}{ Unrelated Variety } \\
\hline UV_IND & Employment by industry & 367 & 3.923 & 0.133 & 3.081 & 4.161 \\
\hline UV_EST & Number of establishment by industry & 367 & 3.862 & 0.058 & 3.595 & 3.999 \\
\hline UV_OCC & Employment by occupation & 367 & 3.904 & 0.096 & 3.318 & 4.092 \\
\hline \multicolumn{7}{|c|}{ Control Variables, MSA-level } \\
\hline EDU & Mean years of schooling & 367 & 13.057 & 0.221 & 12.379 & 14.011 \\
\hline MANUF & Manufacturing employment & 367 & 0.180 & 0.063 & 0.038 & 0.580 \\
\hline PCI & Per capita income & 367 & 102249 & 125107 & 18670 & 124310 \\
\hline
\end{tabular}

Table 1. Descriptive statistics 


\begin{tabular}{lcccccc}
\hline & $(1)$ & $(2)$ & $(3)$ & $(4)$ & $(5)$ & $(6)$ \\
\hline$\Delta$ GES (1) & 1 & & & & & \\
RV_IND (2) & -0.026 & 1 & & & & \\
UV_IND (3) & 0.078 & 0.336 & 1 & & & \\
EDU (4) & 0.243 & 0.370 & 0.239 & 1 & & \\
MANUF (5) & -0.026 & 0.572 & 0.468 & 0.359 & 1 & \\
PCI (6) & 0.101 & 0.343 & 0.432 & 0.450 & 0.664 & 1 \\
\hline
\end{tabular}

Table 2.Correlation Matrix 
Table 3. Baseline models

\begin{tabular}{|c|c|c|c|c|}
\hline & (1) & (2) & (3) & (4) \\
\hline RV_IND & $\begin{array}{l}-0.0003 \\
(0.0010)\end{array}$ & & $\begin{array}{l}-0.0019 \\
(0.0014)\end{array}$ & $\begin{array}{l}-0.0013 \\
(0.0041)\end{array}$ \\
\hline UV_IND & $\begin{array}{c}0.0030 * * * \\
(0.0011)\end{array}$ & & $\begin{array}{c}0.0041 * * * \\
(0.0014)\end{array}$ & $\begin{array}{c}0.0119 * * * \\
(0.0042)\end{array}$ \\
\hline RV_EST & & $\begin{array}{c}0.0003 \\
(0.0015)\end{array}$ & & \\
\hline UV_EST & & $\begin{array}{c}0.0028 * * \\
(0.0012)\end{array}$ & & \\
\hline EDU & $\begin{array}{c}0.1100 * * \\
(0.0425)\end{array}$ & $\begin{array}{c}0.1537 * * * \\
(0.0490)\end{array}$ & $\begin{array}{c}0.2383 * * * \\
(0.0640)\end{array}$ & $\begin{array}{c}0.4399 * * \\
(0.1699)\end{array}$ \\
\hline MANUF & $\begin{array}{l}-0.0002 \\
(0.0010)\end{array}$ & $\begin{array}{l}-0.0004 \\
(0.0008)\end{array}$ & $\begin{array}{c}0.0002 \\
(0.0011)\end{array}$ & $\begin{array}{l}-0.0008 \\
(0.0040)\end{array}$ \\
\hline PCI & $\begin{array}{l}-0.0001 \\
(0.0009)\end{array}$ & $\begin{array}{c}0.0006 \\
(0.0009)\end{array}$ & $\begin{array}{l}-0.0012 \\
(0.0013)\end{array}$ & $\begin{array}{l}-0.0002 \\
(0.0038)\end{array}$ \\
\hline Reg. Dummies & Y & $\mathrm{Y}$ & $\mathrm{Y}$ & $\mathrm{Y}$ \\
\hline Time Dummies & $\mathrm{Y}$ & $\mathrm{Y}$ & $\mathrm{N}$ & $\mathrm{Y}$ \\
\hline$N$ & 730 & 730 & 365 & 730 \\
\hline$R^{2}$ & 0.474 & 0.475 & 0.232 & 0.474 \\
\hline
\end{tabular}

Notes: N= (367 MAs x 2 time periods). OLS regressions at MA level. Dependent variable: average log-difference of green employment share growth over the periods 2006-2009 and 2010-2014 (Columns (1) and (2)); the average log-difference of green employment share growth over the period 2006-2014 (Column (3)); the growth rate of green employment share calculated using the first and final year of the periods: 2006-2009 and 2010-2014 (Column (4)). Regional dummies refer to Midwest, Northeast, South and West geographical areas. Independent variables are included at the start of the period. Robust standard errors clustered by US Federal State in parentheses. All models are weighted by MA population at the start of the period. $* \mathrm{p}<0.1, * * \mathrm{p}<0.05, * * * \mathrm{p}<0.01$. 
Table 4. Extension: across occupational groups

\begin{tabular}{lccccc}
\hline & $\begin{array}{c}(1) \\
\text { Non-Routine } \\
\text { Cognitive }\end{array}$ & $\begin{array}{c}\text { Non-Routine } \\
\text { Interactive }\end{array}$ & $\begin{array}{c}\text { Non-Routine } \\
\text { Manual }\end{array}$ & $\begin{array}{c}(4) \\
\text { Routine } \\
\text { Cognitive }\end{array}$ & $\begin{array}{c}\text { Routine } \\
\text { Manual }\end{array}$ \\
\hline RV_IND & 0.0022 & $0.0043^{*}$ & 0.0004 & -0.0002 & -0.0008 \\
& $(0.0021)$ & $(0.0023)$ & $(0.0013)$ & $(0.0017)$ & $(0.0012)$ \\
UV_IND & 0.0009 & 0.0009 & $0.0026^{* *}$ & 0.0004 & $0.0044^{* * *}$ \\
& $(0.0018)$ & $(0.0016)$ & $(0.0012)$ & $(0.0014)$ & $(0.0013)$ \\
EDU & 0.0384 & 0.0139 & -0.0222 & 0.0397 & 0.0271 \\
& $(0.0687)$ & $(0.0856)$ & $(0.0621)$ & $(0.0930)$ & $(0.0557)$ \\
MANUF & 0.0017 & 0.0012 & -0.0007 & 0.0007 & -0.0009 \\
PCI & $(0.0025)$ & $(0.0016)$ & $(0.0010)$ & $(0.0015)$ & $(0.0010)$ \\
& -0.0003 & 0.0018 & 0.0001 & -0.0013 & -0.0009 \\
Reg. Dummies & $(0.0024)$ & $(0.0020)$ & $(0.0011)$ & $(0.0020)$ & $(0.0009)$ \\
Time Dummies & $\mathrm{Y}$ & $\mathrm{Y}$ & $\mathrm{Y}$ & $\mathrm{Y}$ & $\mathrm{Y}$ \\
\hline \multirow{2}{*}{$N$} & $\mathrm{Y}$ & $\mathrm{Y}$ & $\mathrm{Y}$ & $\mathrm{Y}$ & $\mathrm{Y}$ \\
$R^{2}$ & 730 & 730 & 730 & 730 & 730 \\
\hline
\end{tabular}

Notes: N= (367 MAs x 2 time periods). OLS regressions at MA level. Dependent variables: average log-difference of green employment share growth over the periods 2006-2009 and 2010-2014 (Columns (1) and (2). Regional dummies refer to Midwest, Northeast, South and West geographical areas. Independent variables are included at the start of the period. Robust standard errors clustered by US Federal State in parentheses. All models are weighted by MA population at the start of the period. $* \mathrm{p}<0.1, * * \mathrm{p}<0.05, * * * \mathrm{p}<0.01$. 
Table 5. Extension: alternative UV, RV constructs across occupational groups

\begin{tabular}{|c|c|c|c|c|c|c|}
\hline & $\begin{array}{l}\text { (1) } \\
\text { All }\end{array}$ & $\begin{array}{c}\text { (2) } \\
\text { Non-Routine } \\
\text { Cognitive }\end{array}$ & $\begin{array}{c}\text { (3) } \\
\text { Non-Routine } \\
\text { Interactive }\end{array}$ & $\begin{array}{c}\text { (4) } \\
\text { Non-Routine } \\
\text { Manual }\end{array}$ & $\begin{array}{c}\text { (5) } \\
\text { Routine } \\
\text { Cognitive }\end{array}$ & $\begin{array}{c}(6) \\
\text { Routine } \\
\text { Manual }\end{array}$ \\
\hline RV_IND & $\begin{array}{c}-0.0002 \\
(0.0012)\end{array}$ & $\begin{array}{c}0.0016 \\
(0.0020)\end{array}$ & $\begin{array}{c}0.0025 \\
(0.0022)\end{array}$ & $\begin{array}{c}0.0003 \\
(0.0014)\end{array}$ & $\begin{array}{c}-0.0007 \\
(0.0018)\end{array}$ & $\begin{array}{c}-0.0006 \\
(0.0014)\end{array}$ \\
\hline UV_IND & $\begin{array}{c}0.0031 * * * * \\
(0.0011)\end{array}$ & $\begin{array}{c}0.0008 \\
(0.0016)\end{array}$ & $\begin{array}{c}0.0002 \\
(0.0016)\end{array}$ & $\begin{array}{l}0.0024 * \\
(0.0013)\end{array}$ & $\begin{array}{c}0.0003 \\
(0.0015)\end{array}$ & $\begin{array}{c}0.0043 * * * \\
(0.0014)\end{array}$ \\
\hline RV_OCC & $\begin{array}{c}-0.0005 \\
(0.0009)\end{array}$ & $\begin{array}{c}-0.0005 \\
(0.0021)\end{array}$ & $\begin{array}{c}0.0011 \\
(0.0022)\end{array}$ & $\begin{array}{c}0.0010 \\
(0.0011)\end{array}$ & $\begin{array}{c}0.0001 \\
(0.0018)\end{array}$ & $\begin{array}{c}0.0006 \\
(0.0013)\end{array}$ \\
\hline UV_OCC & $\begin{array}{c}0.0003 \\
(0.0014)\end{array}$ & $\begin{array}{c}0.0056 \\
(0.0035)\end{array}$ & $\begin{array}{c}0.0115 * * \\
(0.0045)\end{array}$ & $\begin{array}{c}-0.0013 \\
(0.0019)\end{array}$ & $\begin{array}{l}0.0041 * \\
(0.0022)\end{array}$ & $\begin{array}{c}-0.0030 \\
(0.0018)\end{array}$ \\
\hline EDU & $\begin{array}{c}0.1090 \\
(0.0676)\end{array}$ & $\begin{array}{c}-0.0835 \\
(0.0949)\end{array}$ & $\begin{array}{c}-0.2612 \\
(0.1798)\end{array}$ & $\begin{array}{l}-0.0032 \\
(0.0966)\end{array}$ & $\begin{array}{c}-0.0544 \\
(0.1079)\end{array}$ & $\begin{array}{c}0.0869 \\
(0.0826)\end{array}$ \\
\hline MANUF & $\begin{array}{l}-0.0000 \\
(0.0011)\end{array}$ & $\begin{array}{c}0.0024 \\
(0.0026)\end{array}$ & $\begin{array}{c}0.0018 \\
(0.0017)\end{array}$ & $\begin{array}{l}-0.0011 \\
(0.0010)\end{array}$ & $\begin{array}{c}0.0010 \\
(0.0016)\end{array}$ & $\begin{array}{l}-0.0014 \\
(0.0011)\end{array}$ \\
\hline PCI & $\begin{array}{c}-0.0001 \\
(0.0010)\end{array}$ & $\begin{array}{l}-0.0011 \\
(0.0023)\end{array}$ & $\begin{array}{c}0.0003 \\
(0.0018)\end{array}$ & $\begin{array}{c}0.0004 \\
(0.0010)\end{array}$ & $\begin{array}{c}-0.0019 \\
(0.0021)\end{array}$ & $\begin{array}{c}-0.0004 \\
(0.0010)\end{array}$ \\
\hline Reg. Dummies & $\mathrm{Y}$ & $\mathrm{Y}$ & $\mathrm{Y}$ & $\mathrm{Y}$ & $\mathrm{Y}$ & $\mathrm{Y}$ \\
\hline Time Dummies & $\mathrm{Y}$ & Y & $\mathrm{Y}$ & $\mathrm{Y}$ & $\mathrm{Y}$ & $\mathrm{Y}$ \\
\hline$N$ & 730 & 730 & 730 & 730 & 730 & 730 \\
\hline$R^{2}$ & 0.474 & 0.125 & 0.236 & 0.338 & 0.320 & 0.352 \\
\hline
\end{tabular}

Notes: N= (367 MAs x 2 time periods). OLS regressions at MA level using dependent variables measured as: the average log-difference of green employment share growth over the periods 20062009 and 2010-2014 (Column 1). Regional dummies refer to Midwest, Northeast, South and West geographical areas. Independent variables are included at the start of the period. Robust standard errors clustered by US Federal State in parentheses. All models are weighted by MA population at the start of the period. ${ }^{*} \mathrm{p}<0.1,{ }^{*} \mathrm{p}<0.05,{ }^{* * *} \mathrm{p}<0.01$. 